\title{
Low Temperature Gas Sensing Coatings Made through Wet Chemical Deposition of Niobium Doped Titanium Oxide Colloid
}

\author{
Naji Al Dahoudi \\ Physics Department, Al Azhar University, Gaza, Palestine. \\ Email: naji@alazhar-gaza.edu \\ Received January $6^{\text {th }}, 2011$; revised February $28^{\text {th }}, 2011$; accepted March $17^{\text {th }}, 2011$.
}

\begin{abstract}
Niobium doped titanium oxide $\left(\mathrm{TiO}_{2}\right)$ colloid was synthesized to fabricate a hydrogen gas sensor layer on oxidized silicon wafer substrate. The layers were obtained using spin coating technique and then heated in air at $500^{\circ} \mathrm{C}$ for $30 \mathrm{~min}$. The doping of $\mathrm{TiO}_{2}$ led to a significant enhancement of the sensitivity of the layer especially at low operating temperature. The effect of doping was found effective of operating the sensor at relatively low temperature $\left(150^{\circ} \mathrm{C}\right)$. The layers show a very smooth nanostructure with average roughness of less than $0.5 \mathrm{~nm}$. The behavior of the sensing characteristics of such layers was discussed related to their chemical compositions, morphology and their crystalline structure. The morphological and structural characteristics of the layers were studied through X-ray diffraction (XRD) and Atomic force microscopy (AFM).
\end{abstract}

Keywords: Colloid, Titanium Oxide, Niobium, Gas Sensor, Spin Coating

\section{Introduction}

Semiconducting oxide materials have been subjected to much of developing researches for their use as essential components in many industrial applications. Extensive researches have been done to develop devices that can detect inflammable and toxic gases using such materials. Semiconducting metal oxides such as tin oxide $\left(\mathrm{SnO}_{2}\right)$, zinc oxide $(\mathrm{ZnO})$, indium oxide $\left(\mathrm{In}_{2} \mathrm{O}_{3}\right)$, and titanium oxide $\left(\mathrm{TiO}_{2}\right)$ have been widely used as active materials in solid-state gas sensing devices [1-5]. Titanium oxide $\left(\mathrm{TiO}_{2}\right)$ is one of the most important materials that have a wide multidisciplinary applications, such as photocatalytic applications (self cleaning and self sterilization), inorganic membrane material for ultrafilteration, photoelectric properties, and antireflection optical thin films and as gas sensing materials [6-9]. The gas sensing mechanism of such materials can be understood as a function of the adsorption of gases on the semiconductor surface and the corresponding change in the electrical conductivity of the material. The adsorption of some gases species leads to the formation of charge depletion layer affecting the transfer of the charge carriers from site to another. The adsorption of oxidizing gases such as $\mathrm{NO}$ or $\mathrm{O}_{3}$ lead to an increase of the sensor resistance, however reducing gases such as $\mathrm{H}_{2}$ or $\mathrm{CH}_{3} \mathrm{OH}$ causes a reduction in the adsorbed oxygen leading to a decrease of the electrical resistance of the sensor material $[7,10,11]$. Nanostructured materials possessing very large specific area which makes them very attractive to realize chemical or physical sensors, as the solid state sensing mechanism is governed primarily by the available surface area. Furthermore, the wet chemical sol-gel coating is becoming a real candidate process compared with the established vacuum processes, because of the low cost, the higher flexibility regarding the geometry of substrates and the high coating quality.

Detecting hydrogen gas is an important issue for industrial process control, combustion control, and as well for some medical application where some bacterial infection can be detected using such sensor [12]. In this work, a colloidal sol of niobium doped titanium oxide was prepared for obtaining sensor layers that can detect hydrogen gas. The layers were obtained using spin coating process.

\section{Experimental}

\subsection{Coating Colloid}

The coating sols were prepared by the hydrolysis of Ti- 
tanium and Niobium alkoxides. For a pure $\mathrm{TiO}_{2}$ colloid, a 0.0015 mole of Titanium isopropoxide was mixed in 0.105 mole of 2-methoxyethanol and stirred at RT for 10 min. A $0.1 \mathrm{~g}$ of bidistilled water in Methoxy ethanol was added to the alkoxide solution under stirring for the hydrolysis at RT for $1 \mathrm{hr}$. The addition of water resulted in a precipitation, where a hydrophobic colloidal was formed. The resulted solution was redipersed by adding a $0.5 \mathrm{~g}$ of nitric acid in Methoxy ethanol. A clear colloid was formed, which is then filtered using a $0.2 \mu \mathrm{m}$ filter before the deposition procedure. For the Niobium doped colloid, different concentrations between $2 \mathrm{~mol} \%$ to 30 mol\% of Niobium (V) $n$-Butoxide was added to the titanium alkoxide solution, and the rest of the method as before.

Film Formation: The layers were formed by depositing the coating colloids onto a clean $\mathrm{Si} / \mathrm{SiO}_{2}$ wafer substrate using the spin coating technique. Three layers was obtained and between each step the wet layer was subjected to a drying process at $150^{\circ} \mathrm{C}$ for $5 \mathrm{~min}$., and then all layers were heated in an oven at $500^{\circ} \mathrm{C}$ for $30 \mathrm{~min}$. A structured gold film was sputtered onto the layers, and then a cupper electrode contact was made for the gas sensing measurements.

\subsection{Characterizations}

The gas sensing properties of the assembled layers were carried out using a computer controlled set-up, including a gas chamber, flow meters (Bronkhorst, Germany), gas delivery pipes, a heating plate with a PID temperature controller and a source meter (Keithly 2601). Air was used as the carrier gas and a mixture of $\mathrm{N}_{2}$ and $\mathrm{H}_{2}$ $\left(\mathrm{N}_{2} / \mathrm{H}_{2}: 95 / 5\right)$ as doping gases. Interdigitated front electrodes were deposited and contacted with copper wires using silver paste. The gas was delivered in the required concentration in form of short pulses of $40 \mathrm{~s}$ duration. The sensitivity of the samples was defined as $\mathrm{S}=\mathrm{R}_{\mathrm{a}} / R_{g}$ where $\mathrm{R}_{\mathrm{a}}$ and $\mathrm{R}_{\mathrm{g}}$ are the measured electrical resistance of the samples in air and gas, respectively. The thickness of the layers as well as their refractive indices were carried out using a high resolution Ellipsometer (DR 155, Germany) operated at a wavelength of $632 \mathrm{~nm}$. The structural properties of the layers (determination of the phase and crystal size) were carried out using the $\mathrm{X}$ ray diffractometer. The topography of the layers has been measured using an atomic force microscopy (AFM) (SIS, Nanostation, Germany).

\section{Results and Discussions}

The thickness of the three layered sensor for pure and doped $\mathrm{TiO}_{2}$ was measured after the ellipsometry to be ranged between 160 - $170 \mathrm{~nm}$. The same value was confirmed after a cross sectional image done by the SEM. The microstructure of the obtained $\mathrm{TiO}_{2}$ and $\mathrm{Nb}$ doped

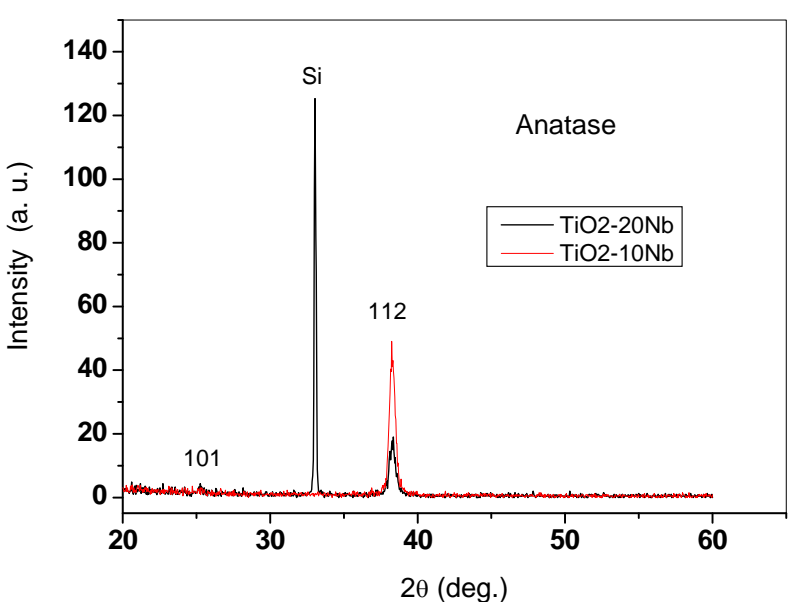

Figure 1. The XRD pattern for spin coated $10 \%$ and $20 \%$ $\mathrm{Nb}$ doped $\mathrm{TiO}_{2}$ layers deposited on $\mathrm{Si}$ substrate and heated at $500^{\circ} \mathrm{C}$.

$\mathrm{TiO}_{2}$ thin layers on $\mathrm{Si} / \mathrm{SiO}_{2}$ substrates were examined via XRD and those results for $10 \%$ and $20 \% \mathrm{Nb}$ doping are shown in Figure 1. The XRD pattern exhibited only peaks related to the anatase structure and no rutile structure was observed and also no Niobium related phase was found. The anatase phase was expected, as the heating temperature of the layers is relatively low $\left(500^{\circ} \mathrm{C}\right)$. It is reported that the deposited amorphous $\mathrm{TiO}_{2}$ film crystallizes into anatase structure at around $350^{\circ} \mathrm{C}$ and the anatase-rutile transformation occurs at high temperatures of $600^{\circ} \mathrm{C}-900^{\circ} \mathrm{C}$ [13]. The tendency of the formation of anatase phase is enhanced by the doping of Niobium, where the 112 peak for the $20 \% \mathrm{Nb}$ is sharper than that of the $10 \%$ one. The refractive index of the layers measured using the ellipsometry show a value of 2.5 of $10 \%$ $\mathrm{Nb}$ doping $\mathrm{TiO}_{2}$, and 2.54 for $20 \% \mathrm{Nb}$ doping $\mathrm{TiO} 2$, which is closer to the theoretical anatase phase.

The surface morphology of the three $\mathrm{TiO}_{2}$ layers is exhibited in Figures 2(a,b) using the AFM. The surface of all layers shows a very fine and smooth structure with an average roughness less than $0.5 \mathrm{~nm}$. This smooth structure of the layers surface refers to the high monodispersion of the crystalline nanoparticles in the coating sol and due to the low temperature annealing $\left(500^{\circ} \mathrm{C}\right)$ of the wet layers. The SEM technique was used to test the morphology of the surface of the layer, however because of the smoothness of the surface, a blank surface was only observed.

At the operating temperatures 150,200 and $250^{\circ} \mathrm{C}$ the electrical resistance of the pure and doped $\mathrm{TiO}_{2}$ layers were measured in air. Figure 3 shows the variation of the electrical resistance of the sensor layers in air as a function of the $\mathrm{Nb}$ doping concentration from 0 to $30 \mathrm{~mol} \%$ at different operating temperature. Similar to all semi- 


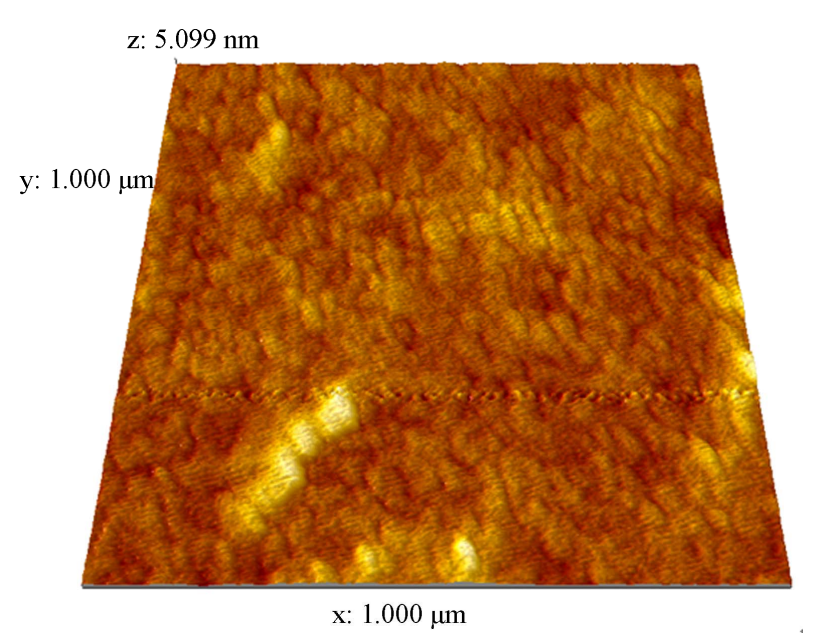

(a)

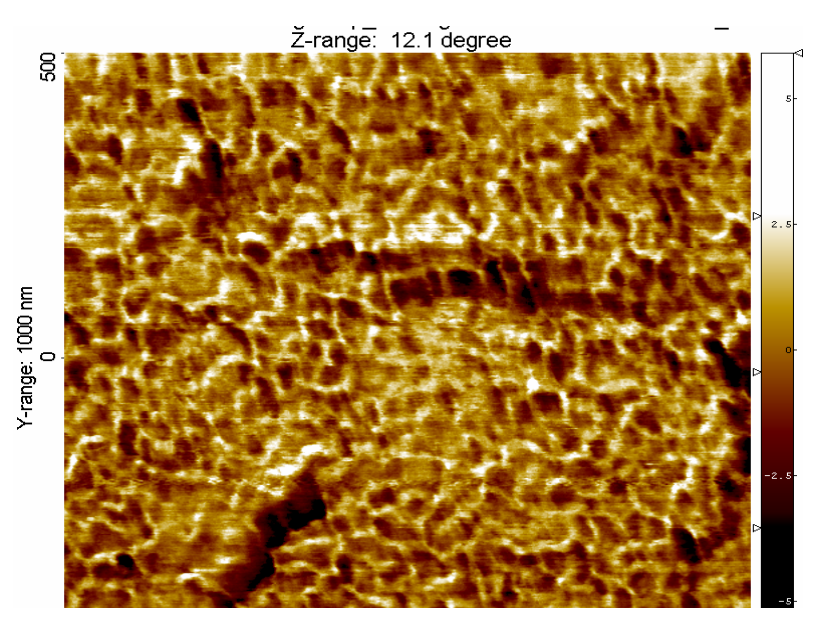

(b)

Figure 2. (a) Atomic force microscopy (AFM) of the surface $(1 \mu \mathrm{m} \times 1 \mu \mathrm{m})$ of the $\mathrm{TiO}_{2}$ layers deposited on Si wafer; (b) The scanning surface potential microscopy (SSPM) for the sample in (a).

conducting oxides, the material shows a reduction of the electrical resistance by raising the operating temperature, which is understood as a result of the increase of charge carrier density in the conduction band. The effect of $\mathrm{Nb}$ doping leads to further gradual decrease of the electrical resistance of the coatings. This indicates that the $\mathrm{Nb}$ in corporation into $\mathrm{TiO}_{2}$ lattice leading to a reducing effect, which means adding extra free charges to the lattice. It is observed that the Niobium doping for concentrations higher than $10 \%$ is not effective for further decrease in the electrical resistance of the doped films, however in some samples an increase of the electrical resistance is observed beyond $10 \%$ of $\mathrm{Nb}$ doping. The increasing electrical resistance or decreasing conductivity with increasing $\mathrm{Nb}$ concentration is attributed to the pair forma-

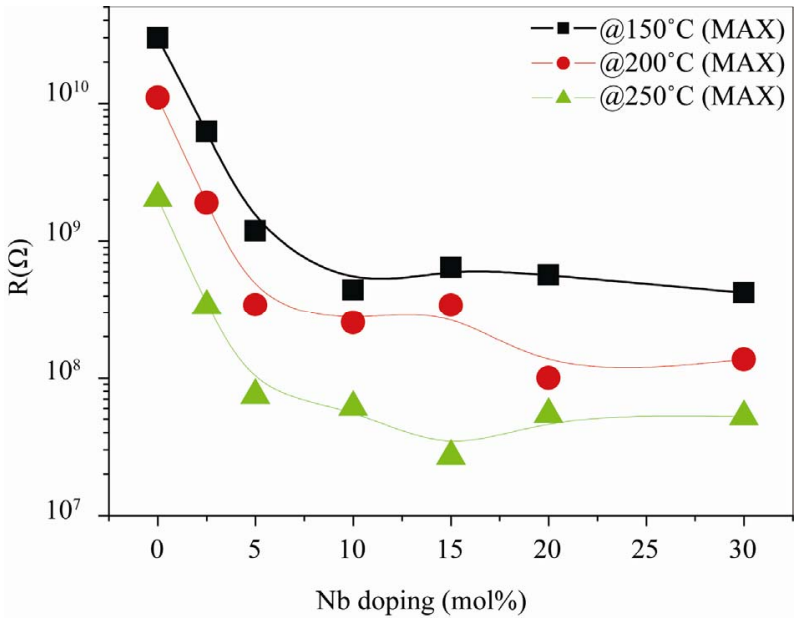

Figure 3. Variation of electrical resistance of pure and $\mathrm{Nb}$ doped $\mathrm{TiO}_{2}$ layers at different operating temperatures.

tion, by which charge carriers are localized between the two Nb ions [10].

The sensitivity of the hydrogen gas for pure and $\mathrm{Nb}$ doped $\mathrm{TiO}_{2}$ layers measured at different operating temperatures 150, 200 and $250^{\circ} \mathrm{C}$ is shown in Figure 4. It is observed that the doping of niobium enhances the sensitivity of the sensor effectively especially at low operating temperature. At higher operating temperature $\left(\mathrm{T}=250^{\circ} \mathrm{C}\right)$ the sensitivity of the layers decreases and the doping of niobium add no further enhancement compared with the values obtained for pure $\mathrm{TiO}_{2}$ layers. The smaller crystallite size of nanocrystallite niobium-doped titanium oxide than that of undoped-titanium oxide benefits the catalytic activity for sensing gas [11]. It is found that $5 \mathrm{~mol} \%$ of Niobium doping operated at $\mathrm{T}=150^{\circ} \mathrm{C}$ gives the best results, where at this doping concentration it pocesses a sensitivity 8 times greater than pure $\mathrm{TiO}_{2}$. The doping of niobium lead to a reduction of the operating temperature of the sensor, where for example at $5 \% \mathrm{Nb}$ doping the sensitivity is 8.5 at $\mathrm{T}=150^{\circ} \mathrm{C}$ which decreases to 1.5 by increasing the operating temperature to $250^{\circ} \mathrm{C}$. However, for pure $\mathrm{TiO}_{2}$, the sensitivity is becoming higher by increasing the operating temperature. The inset in Figure 4 shows the measured sensitivity in \% in relation with the $\mathrm{Nb}$ concentration at different operating temperatures. These results show that such sensors are adequate to be operated at low temperature with higher sensitivity by the niobium doping.

The decrease of the electrical resistance which is believed due to the absorbance of the sensing gas is anticipated to a reduction of the surface oxygen species $\mathrm{O}^{-}$ such as $\mathrm{H}_{2}+\mathrm{O}^{-} \rightarrow \mathrm{H}_{2} \mathrm{O}+\mathrm{e}^{-}$. This behavior is reversible by flowing air into the gas chamber, where electron recombination leading to $\mathrm{O}^{-}$regeneration. Figure 5 

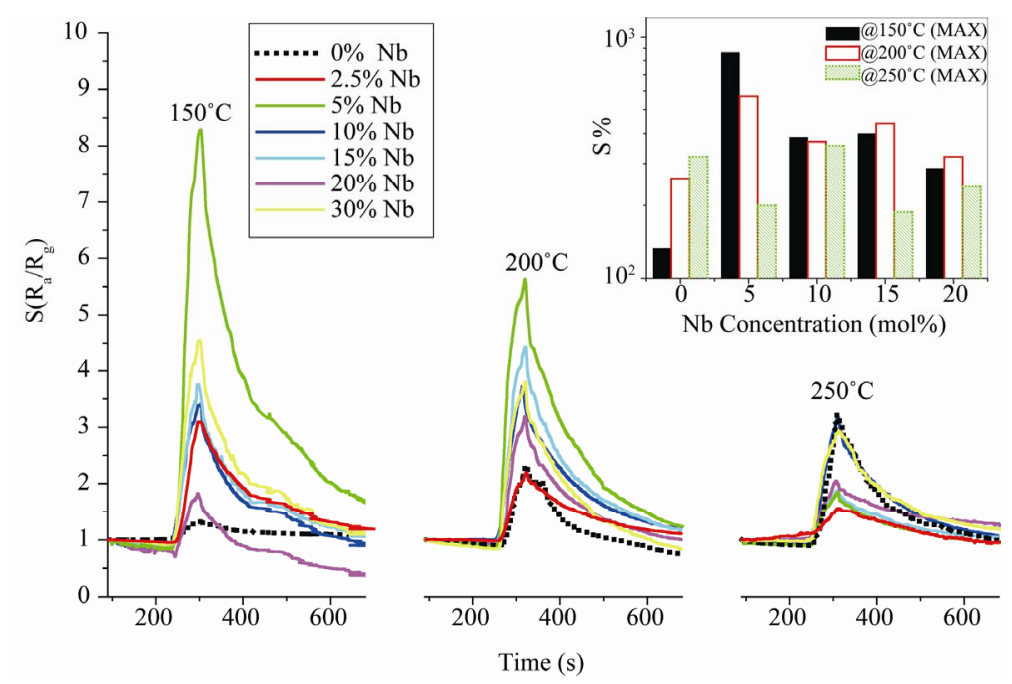

Figure 4. The sensitivity of the hydrogen gas for layers of pure and different $\mathrm{Nb}$ doped $\mathrm{TiO}_{2}$ layers at different operating temperature. The inset shows the sensitivity percent as a function of the $\mathrm{Nb}$ doping concentration.

shows the response and the recovery states of $5 \% \mathrm{Nb}$ doped $\mathrm{TiO}_{2}$ layer for different sensing gas concentration. The film exhibit a remarkable sensation at gas concentration of $300 \mathrm{ppm}$. The change in the electrical conductivity is increasing from 1.5 to 5 by increasing the concentration of the gas from 300 to $1300 \mathrm{ppm}$. The film also exhibits faster response time than the recovery time for all gas concentrations. At gas concentration of $1300 \mathrm{ppm}$, the response time is $42 \mathrm{~s}$, where the recovery time is 112 s. This means that the regeneration of the $\mathrm{O}^{-}$species is slower than the reduction process.

\section{Conclusions}

The synthesis of nanocrystalline niobium doped titanium oxide colloid was successful to be deposited on oxidized

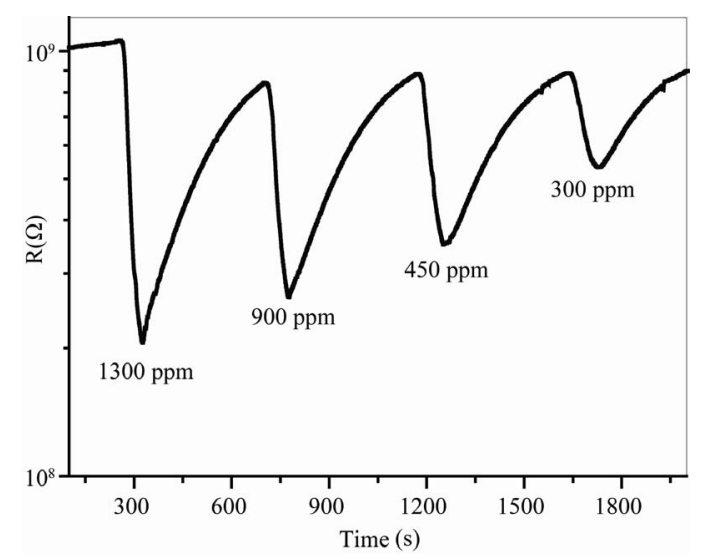

Figure 5. The change of the electrical resistance of $5 \% \mathrm{Nb}$ doped $\mathrm{TiO}_{2}$ layer as a function of the reducing gas concentrations (pulse duration is $40 \mathrm{~s}$, operating temperature @ $\left.150^{\circ} \mathrm{C}\right)$.
Si wafer substrate for producing a hydrogen gas sensor thin film. The coating was carried out using spin coating technique, dried and then heated in air at $500^{\circ} \mathrm{C}$ for 30 min. The obtained layers have a very smooth surface with low average roughness as observed by the AFM and exhibited an anatase phase structure according to the obtained XRD pattern. The niobium doping of $\mathrm{TiO}_{2}$ led to a significant enhancement of the hydrogen gas sensitivity of the layer especially at low operating temperature. The effect of doping was found effective of operating the sensor at relatively low temperature $\left(150^{\circ} \mathrm{C}\right)$. The behavior of the sensing characteristics of such layers was discussed related to their chemical compositions, morphology and the concentration of the hydrogen gas. An observable sensation of the gas was observed clearly at low hydrogen gas concentration.

\section{Acknowledgments}

I would like to thank the German Academic Exchange Service (DAAD) for their short visit scholarship to Germany in 2007 and 2009. Furthermore I would like to thank Prof. Mohammed Es-Souni from the IMST in Kiel and Prof. Rolf Clasen from the Powder Technology for Glass and Ceramics department at the University of Saarland for hosting me during my research study visit to Germany.

\section{REFERENCES}

[1] H. Ogawa, M. Nishikawa and A. Abe, "Hall Measurement Studies and an Electrical Conduction Model of Tin oxide Ultrafine Particle Films," Journal of Applied Physics, Vol. 53, No. 6, 1982, pp. 4448-4455. doi:10.1063/1.331230 
[2] H. Cheong and M. Lee, "Sensing Characteristics and Surface Reaction Mechanism of Alcohol Sensors Based on Doped $\mathrm{SnO}_{2}$," Journal of Ceramic Processing Research, Vol. 7, No. 3, 2006, pp. 183-191.

[3] C. H. Kwon, H. Hong, D. H. Yun, S. Kim, Y. Roh and H. Lee, "Thick-Film Zinc-Oxide Gas Sensor for the Control of Lean Air-to-Fuel Ratio in Domestic Combustion Systems," Sensors and Actuators B: Chemical, Vol. 25, No. 1, 1995, pp. 610-613. doi:10.1016/0925-4005(95)85134-8

[4] S. Shukla, S. Seal, L. Ludwig and C. Parish, "Nanocrystalline Indium Oxide-Doped Tin Oxide Thin Film as Low Temperature Hydrogen Sensor,” Sensors and Actuators B: Chemical, Vol. 97, No. 2-3, 2004, pp. 256-265. doi:10.1016/i.snb.2003.08.025

[5] M. C. Corotta, M. Ferroni, D. Gnani, M. Merli, G. Martinelli, M. C. Casale and M. Notaro,” Pure and Nb-Doped $\mathrm{TiO}_{2}$ as Thick Film Gas Sensors for Environmental Monitoring," Sensors and Actuators B: Chemical, Vol. 58, No. 1-3, 1999, pp. 310-317. doi:10.1016/S0925-4005(99)00148-3

[6] H. Schmidt, M. Akarsu, T. S. Müller, K. Moh, G. Schäfer, D. J. Strauss and M. Naumann, "The Formation of Gradients in Wet Deposited Coatings with Photocatalytically Active Nanoparticles," Research on Chemical Intermediates, Vol. 31, No. 4-6, 2005, pp. 535-553. doi:10.1163/1568567053956680

[7] O. Legrini, E. Oliveros and A. M. Braun, "Photochemical Processes for Water Treatment," Chemical Reviews, Vol. 93, No. 2, 1993, pp. 671-698. doi:10.1021/cr00018a003
[8] R. Kishore, S. N. Singh and B. Das, "Screen Printed Titanium Oxide and PECVD Silicon Nitride as Antireflection Coating on Silicon Solar Cells,” Renewable Energy, Vol. 12, No. 2, 1997, pp. 131-135. doi:10.1016/S0960-1481(97)00030-X

[9] M. Ponce, R. Parra, R. Savu, E. Joanni, P. Bueno, M. Cilense, J. Varela and M. Castro, "Impedance Spectroscopy Analysis of $\mathrm{TiO}_{2}$ Thin Film Gas Sensors Obtained from Water-Based Anatase Colloids," Sensors and Actuators B, Vol. 139, No. 2, 2009, pp. 447-452. doi:10.1016/j.snb.2009.03.066

[10] Varghese, D. Gong, M. Paulose, K. Ong and C. Grimes, "Hydrogen Sensing Using Titania Nanotubes," Sensors and Actuators B: Chemical, Vol. 93, No. 1-3, 2003, pp. 338-344. doi:10.1016/S0925-4005(03)00222-3

[11] L. S. Hsu, R. Rujkorakarn, J. R. Sites, and C. Y. She, "Thermally Induced Crystallization of Amorphous-Titania Film”, Journal of Applied Physics, Vol. 59, No. 10, 1986, pp. 3475-3480. doi:10.1063/1.336817

[12] I. Song, "Defect Structure and DC Electrical Conductivity of Titanium Dioxide-Niobium Dioxide Solid Solution”, Ph.D. Thesis, Case Western Reserve University, Cleveland, 1990.

[13] M. Lee, C. Shih, S. Fang, H. Tu and C. Ho, "Preparation of Niobium-Doped Titanium Oxide Film by Liquid Phase Deposition," Japanese Journal of Applied Physics, Vol. 46, No. 4A, 2007, pp. 1653-1655. doi:10.1143/JJAP.46.1653 